\title{
Double-blind comparison of a single dose and a five- day course of metronidazole in the treatment of trichomoniasis*
}

\author{
R. N. THIN, M. A. E. SYMONDS, R. BOOKER, S. COOK, AND F. LANGLET \\ From St Bartholomew's and Eastern Hospitals, London
}

SUMMARY Although there have been reports of the results of treating trichomoniasis with metronidazole $2 \mathrm{~g}$ in a single dose, no randomised double-blind comparison of this treatment with a multiple-dose regimen has been reported.

In such a comparison, 96 women were treated with metronidazole $2 \mathrm{~g}$ in a single dose and 96 women with metronidazole $400 \mathrm{mg}$ twice daily for five days. Forty-eight of 52 women followed for 14 days after the single dose were cured, as were 61 of 66 women followed for 14 days after the start of the five-day regimen. These results compare favourably with previous reports. Side effects were trivial, and we recommend the single $2-\mathrm{g}$ dose, for it is effective, economical, and can be given under supervision in the clinic.

\section{Introduction}

The history of the treatment of trichomoniasis was briefly reviewed by Willcox (1977), who noted the gradual reduction in duration of treatment and mentioned that metronidazole $2 \mathrm{~g}$ in a single dose gave reasonably satisfactory results. Csonka (1971) appears to have been the first to use this regimen. He compared the findings in 38 patients treated with metronidazole $2 \mathrm{~g}$ with those in 49 patients treated with metronidazole $200 \mathrm{mg}$ three times daily for seven days; $82 \%$ of the former group and $94 \%$ of the latter group were regarded as cured after follow up for three months. Woodcock (1972) and Morton (1972) reported similar cure rates for treatment with metronidazole $2 \mathrm{~g}$ in a single dose.

In 1974 cure rates with metronidazole $200 \mathrm{mg}$ three times daily for seven days or $\mathbf{4 0 0} \mathrm{mg}$ twice daily for five days were higher in this department at $98.4 \%$ in a study of 60 patients treated with each regimen and followed for 14 days after the start of treatment (Thin, unpublished observations). The 2-g single dose was therefore held in reserve for patients with recurrence (that is, reinfection or treatment failure). In 1976 most cases were cured with the single-dose

"Presented at the Spring Meeting of the MSSVD, May 1979, in Lubeck, West Germany

Address for reprints: Dr R. N. Thin, Department of Genital Medicine, St Bartholomew's Hospital, London EC1A 7BE

Received for publication 2 April 1979 treatment after there had been recurrence on a longer course. A double-blind comparison of metronidazole in a single $2-\mathrm{g}$ dose with $400 \mathrm{mg}$ of the same drug given twice daily for five days was therefore arranged and the results are reported here.

\section{Patients and methods}

\section{PATIENTS}

Female patients with vaginal trichomoniasis were studied. All women in whom Trichomonas vaginalis was identified were included except those itinerant patients who were unable to attend for two weeks after the start of treatment and pregnant women.

\section{INVESTIGATIONS}

A wet preparation was made by mixing vaginal secretion with saline on a slide and examining it under a microscope fitted with a $\times 40$ objective. Another sample was inoculated into trichomonas culture medium (Medical Wire and Equipment Co., Bath).

\section{TREATMENT}

Metronidazole (Flagyl, May \& Baker Ltd) 400-mg tablets and identical placebo tablets were packed in individual patient packs, numbered, and randomly arranged so that the patient either received metronidazole $2 \mathrm{~g}$ immediately, followed by one placebo tablet twice daily for five days, or five placebo tablets immediately followed by metronidazole $400 \mathrm{mg}$ twice daily for five days. No- 
one in the clinic had access to the treatment code until after treatment and follow up had been completed.

\section{FOLLOW-UP ASSESSMENT}

Patients were asked to return seven and 14 days after the start of therapy; wet films and cultures were repeated at each visit.

Although two clinics took part in the study, they are both supervised by the same consultants; the same batch of drugs was used, as were the same laboratory methods and the same batches of culture medium.

In assessing results, treatment failure was defined as reappearance of trichomonads within 14 days of the start of treatment in a patient who denied sexual contact. Reinfection was defined as reappearance of trichomonads in a patient who admitted further sexual contact. Recurrence was treatment failure plus reinfection.

\section{Results}

Ninety-six patients were treated with each drug regimen. The patients in the two groups were similar in age distribution, marital state, country of birth, and parity.

Among those treated with metronidazole $2 \mathrm{~g}, 70$ patients were seen at seven days (including one with treatment failure and one who had a reinfection) and 52 patients were seen at 14 days (including two who had a reinfection) (Table). Thus, the total number of failures with this regimen was one $(1.9 \%$ of the 52 followed for 14 days) and the total number of recurrences was four (7.7\% of the 52 followed for 14 days), giving an overall cure rate of $92.3 \%$ at 14 days.

Among those treated with metronidazole $400 \mathrm{mg}$ twice daily for five days, 75 patients were seen seven days after the start of treatment, including one with treatment failure but none with reinfection, and 66 patients were seen 14 days after the start of treatment, including two with treatment failure and two with reinfection. The total number of failures was three (4.5\% of the 66 followed for 14 days), and the total number of recurrences was five $(7.6 \%$ of the
66 followed for 14 days), giving a cure rate of $92.4 \%$. The marginally better results with the single-dose regimen are not statistically different from those with the five-day regimen.

No patient reported side effects with the five-day regimen. Nausea, vomiting, and dizziness were each reported by one patient with the single-dose regimen. The patient who vomited was withdrawn.

\section{Discussion}

The overall cure rate of $48(92.3 \%)$ out of 52 patients followed for 14 days after metronidazole $2 \mathrm{~g}$ cannot be compared directly with the findings in other studies as they do not give figures for cures at 14 days. Results from some other studies will be given for approximate comparisons.

In open comparative trials, Csonka (1971) reported cure in approximately $40(86.9 \%)$ of 46 patients given metronidazole $2 \mathrm{~g}$ and seen one month later, and Woodcock (1972) reported cure in 51 $(85.0 \%)$ of 60 patients followed for one to four weeks after treatment with metronidazole $2 \mathrm{~g}$. In a non-comparative study, Morton (1972) reported cure in $97(82.2 \%)$ of 118 women followed for one to three weeks after treatment with the same dose.

Our findings should also be compared with those obtained using other preparations. In a noncomparative study, Jones (1972) reported cure in 149 $(93.7 \%)$ of 159 women treated with nimorazole $2 \mathrm{~g}$ in a single dose and seen at least once after treatment. Tinidazole $2 \mathrm{~g}$ in a single dose has given cure rates of $81-100 \%$ according to a review published by Sawyer et al. (1976). In a comparative trial, Notowicz et al. (1977) reported cure in $67(88.2 \%)$ of 76 women seen one to three weeks after a single dose of carnidazole $2 \mathrm{~g}$.

The cure rate of $61(92.4 \%)$ out of 66 patients followed for 14 days after starting the five-day course compares favourably with cure in $181(91.4 \%)$ of 198 women treated with the same regimen reported by McClean (1971). In an open comparative trial, McClean (1972) also reported cure in $37(82.2 \%)$ of 45 patients given the same dose.

It should be remembered that we used arbitrary

Table Summary of results

\begin{tabular}{|c|c|c|c|c|c|c|c|c|c|c|c|}
\hline \multirow{4}{*}{$\begin{array}{l}\text { Treatment } \\
\text { regimen }\end{array}$} & \multirow{4}{*}{$\begin{array}{l}\text { No. of patients } \\
\text { treated }\end{array}$} & \multicolumn{10}{|c|}{ Duration of follow up (days) } \\
\hline & & \multicolumn{5}{|l|}{ Seven } & \multicolumn{5}{|l|}{14} \\
\hline & & \multirow[b]{2}{*}{ No. seen } & \multicolumn{2}{|c|}{ Failure } & \multicolumn{2}{|c|}{ Reinfection } & \multirow[b]{2}{*}{ No. seen } & \multicolumn{2}{|c|}{ Failure } & \multicolumn{2}{|c|}{ Reinfection } \\
\hline & & & No. & $\%$ & No. & $\%$ & & No. & $\%$ & No. & $\%$ \\
\hline \multirow{2}{*}{$\begin{array}{l}\text { Metronidazole } \\
2 \mathrm{~g} \text { immediately } \\
400 \mathrm{mg} \text { twice } \\
\text { daily for } 5 \text { days }\end{array}$} & 96 & 70 & 1 & 1.4 & 1 & 1.4 & 52 & 0 & & 2 & 3.8 \\
\hline & 96 & 75 & 1 & 1.3 & 0 & & 66 & 2 & 3.0 & 2 & 3.0 \\
\hline
\end{tabular}


definitions of treatment failure and reinfection in the present series. Treatment failure in some patients prescribed the five-day course may have been due to failure to take the treatment as directed. Some cases classed as reinfections may have been due to treatment failure.

The results of this double-blind trial compare favourably with these reports, and, in particular, the results of treatment with metronidazole $2 \mathrm{~g}$ are better than those quoted by Woodcock (1972) and Morton (1972). Although the only side effects reported were with the single-dose regimen, we believe that they were trivial, and we recommend metronidazole $2 \mathrm{~g}$ in a single dose. This has the advantages of economy and the drug can be given under supervision in the clinic.

We are grateful to Dr J. Goulton of May \& Baker Ltd, for supplying active and placebo tablets and to Dr J. Farwell of St Bartholomew's Hospital for packing the tablets and arranging the randomisation. We also thank Sister Boutell and the staff of both clinics for their enthusiastic co-operation.

\section{References}

Csonka, G. W. (1971). Trichomonal vaginitis treated with one dose of metronidazole. British Journal of Venereal Diseases, 47, 456-458.

Jones, J. P. (1972). Treatment of trichomoniasis with a single dose of nimorazole (Nitrimidazine). British Journal of Venereal Diseases, 48, 528-530.

McClean, A. N. (1971). Treatment of trichomoniasis in the female with a 5-day course of metronidazole (Flagyl). British Journal of Venereal Diseases, 47, 36-37.

McClean, A. N. (1972). Nitrimidazine (Naxogin) compared with metronidazole (Flagyl) in the treatment of trichomonal vaginitis. British Journal of Venereal Diseases, 48, 69-70.

Morton, R. S. (1972). Metronidazole in the single-dose treatment of trichomoniasis in men and women. British Journal of Venereal Diseases, 48, 525-527.

Notowicz, A., Stolz, E., and De Koning, G. A. J. (1977). First experience with single dose treatment of vaginal trichomoniasis with carnidazole ( $\mathrm{R} 25831)$. British Journal of Venereal Diseases, 53, 129-131.

Sawyer, P. R., Brogden, R. N., Pinder, R. M., Speight, T. M., and Avery, G. S. (1976). Tinidazole; a review of its anti-protozoal activity and therapeutic efficacy. Drugs, 11, 423-440.

Willcox, R. R. (1977). How suitable are available pharmaceuticals for the treatment of sexually transmitted diseases? 1. Conditions presenting as vaginal discharges. British Journal of Venereal Diseases, 53, 314-323.

Woodcock, K. R. (1972). Treatment of trichomonal vaginitis with a single oral dose of metronidazole. British Journal of Venereal Diseases, 48, 65-68. 